\title{
Biological Maternal Grandmother
}

National Cancer Institute

\section{Source}

National Cancer Institute. Biological Maternal Grandmother. NCI Thesaurus. Code C96578.

A female relative who is the biological mother of the biological mother. 